\title{
Diminished Anxiety- and Depression-Related Behaviors in Mice with Selective Deletion of the Tac1 Gene
}

\author{
Andras Bilkei-Gorzo, Ildiko Racz, Kerstin Michel, and Andreas Zimmer \\ Laboratory of Molecular Neurobiology, Department of Psychiatry, University of Bonn, 53105 Bonn, Germany
}

The tachykinin neuropeptide substance $\mathrm{P}$ and its receptor neurokinin 1 have been implicated in the regulation of many physiological and pathological processes, including the control of emotional behaviors. The present study examines mice with a targeted deletion of the Tac1 gene, which encodes the neuropeptides substance $P$ and neurokinin $A$, in animal models relevant to depressive illness and anxiety. In depression-related paradigms, Tac1-deficient mice were more active in the Porsolt's forced-swimming test and the tail-suspension test, and they did not become hyperactive after bulbectomy. Tac1 mutant mice were also less fearful in several animal models of anxiety. They were more active and less affected by the light

Tachykinins are a family of structurally related neuropeptides sharing the C-terminal sequence Phe-X-Gly-Leu-Met- $\mathrm{NH}_{2}$. In mice, they are encoded by two genes, Tac1 and Tac2. Differential splicing of the Tac1 gene gives rise to three distinct precursor proteins, which are further processed into several related peptides. Of these, substance P (SP) and neurokinin A (NKA) are the best characterized and perhaps the most important peptides. Only one neuropeptide, neurokinin $\mathrm{B}(\mathrm{NKB})$, is encoded by the Tac2 gene.

Tachykinins selectively bind and activate the G-proteincoupled receptors NK1R, NK2R, and NK3R. SP is the most potent ligand for NK1R, whereas NKA has the highest affinity for NK2R. However, the receptor-selectivity of these peptides is relatively low. Because NK1R is abundantly expressed in the CNS and NK2R is virtually absent, many of the effects of SP and NKA on the brain therefore may be mediated by NK1R. NKB is a more potent agonist for the NK3R than SP or NKA, and may be its natural ligand.

Because SP is synthesized by nociceptive neurons and released after nociceptive stimulation, SP has been implicated in the modulation of nociceptive signaling. Indeed a vast body of literature from studies using diverse approaches has generally supported a role of SP in spinal nociception (Cao et al., 1998; Zimmer et al., 1998). Nevertheless, attempts to develop NK1R antagonists as antinociceptive drugs have been successful.

More recently, SP has also been implicated in the modulation of emotional behaviors. Limbic structures contain a high density

\footnotetext{
Received Feb. 26, 2002; revised Sept. 5, 2002; accepted Sept. 11, 2002.

This work was supported by grants from the Land Nordrhein-Westphalen (Innovationsprogramm Forschung), the Deutsche Forschungsgemeinschaft (SFB400), and the BONFOR Program. We thank Charlotte Schick and Anne Zimmer for breeding the animals.

Correspondence should be addressed to Andreas Zimmer, Laboratory of Molecular Neurobiology, Department of Psychiatry, University of Bonn, Sigmund-FreudStrasse 25, 53105 Bonn, Germany. E-mail: neuro@uni-bonn.de.

Copyright (C) 2002 Society for Neuroscience $0270-6474 / 02 / 2210046-07 \$ 15.00 / 0$
}

conditions in the central area of the open-field arena; they showed more social interactions in an aversive environment, they were more active in the open areas of an elevated zeromaze, and they had a reduced latency to feed in the ThatcherBritton conflict paradigm. These results demonstrate that tachykinins are powerful mediators of depression-like or anxiety-related behaviors in mice. The tachykinin system therefore may play an important role in the regulation of emotional states and the development of anxiety disorders and depression.

Key words: anxiety; depression; tachykinin; mice; knock-out; stress

of SP terminals and NK1 receptor sites (Honkaniemi et al., 1992; Hurd et al., 1999; Ribeiro-da-Silva and Hokfelt, 2000), and experimental stressors of various types can trigger changes in the content or release of SP and internalization of the NK1R in discrete brain regions. These changes may be involved in behavioral stress responses, because several studies have demonstrated anxiety-like behaviors and conditioned place aversion after the central administration of neurokinin receptor agonists. Antagonists can produce anxiolytic (Teixeira et al., 1996) or anxiogenic (Zernig et al., 1993) effects, depending on the animal species and the location of the injection site. Mice with selective deletion of the gene coding NK1R also showed reduced aggressive behaviors (Rupniak et al., 2001), impaired stress-induced analgesia, and behavioral alterations in several animal models of anxiety and depression.

Support for an involvement of the tachykinin system in the pathophysiology of mood disorders was obtained recently by the demonstration that the NK1R antagonist MK869 had antidepressant effects in a placebo-controlled clinical trial (Kramer et al., 1998). Preclinical studies have shown that the concentration of SP was elevated in the cerebrospinal fluid of depressed patients (Rimon et al., 1984) and in the brain of a rat model of depression (Husum et al., 2001). In the latter model, SP levels were normalized by treatment with lithium, which is used in clinical practice as a mood stabilizer for the treatment of bipolar depression.

We have previously described the generation of a mouse strain with a targeted mutation in the Tacl gene (Zimmer et al., 1998). Tac1-mutant animals cannot produce SP or NKA. They develop normally, are fertile, and care for their offspring. Behavioral studies with these mice have demonstrated that they are less sensitive to nociceptive stimulation in acute and tonic pain models. This phenotype is consistent with a proposed role of SP in nociceptive signaling. In this study, we have used mice with a targeted deletion of the gene Tacl to further investigate the role of the tachykinin system in stress-related behaviors. We demon- 
strate that $\mathrm{Tacl}^{-1-}$ animals display characteristic alterations in animal models of anxiety and depression, which is consistent with a function on tachykinin peptides as modulators of emotional behaviors.

\section{MATERIALS AND METHODS}

Animals. The generation of mice with a targeted mutation of the Tac1 gene on a mixed genetic background has been described previously (Zimmer et al., 1998). To obtain Tac1 mutant mice on an inbred congenic genetic background, we mated heterozygous $\left(\mathrm{Tacl}^{+/-}\right)$mice with wild-type C57BL/6J (The Jackson Laboratory, Bar Harbor, ME) animals for 10 generations. Heterozygous mice from the F10 generation were then intercrossed to generate animals in which both copies of the Tacl gene were deleted (homozygous $\mathrm{Tacl}^{-1-}$ mice). Tac1-1mice for behavioral studies were derived from these homozygous animals. To avoid a genetic drift, we routinely cross out mutants back to wild-type C57BL/6J animals after three generations of homozygous breeding. Animals used in this study were bred in our animal facility. In addition, some wild-type C57BL/6J control animals were purchased from The Jackson Laboratory. These mice were acclimated for at least 2 weeks before testing. We tested male mice (3-4 months old) housed in groups of three to five. Animals were kept in a room with a reversed light/dark cycle (lights on: 9 P.M., off 9 A.M.) for at least 2 weeks before testing. Every experimental group contained 10 mice, unless stated otherwise. The animals were naive to the test situation, they were used only once, and all tests were conducted between 1 and 5 P.M. Food and water was available ad libitum, except for the group of mice tested in the Thatcher-Britton paradigm. These animals were food deprived for $24 \mathrm{hr}$. Care of the animals and conduct of all experiments followed the guidelines of the German Animal Protection Law (issued in 1998).

Drugs. Amitryptiline $\mathrm{HCl}$, imipramine $\mathrm{HCl}$, fluoxetine $\mathrm{HCl}$, diazepam, and buspirone $\mathrm{HCl}$ were purchased from Sigma-Aldrich and solved in saline. Diazepam (Sigma-Aldrich) was dispersed with one drop of Tween 60 in saline. Ethanol (Merck) was diluted with saline.

Forced-swimming test. Animals were treated (10 in each group) intraperitoneally in a volume of $10 \mathrm{ml} / \mathrm{kg}$ with vehicle (saline) or antidepressant. Amitryptiline $(10 \mathrm{mg} / \mathrm{kg})$, imipramine $(5 \mathrm{mg} / \mathrm{kg})$, and fluoxetine $(20 \mathrm{mg} / \mathrm{kg})$ were used as positive control. Thirty minutes later, mice were placed in a Plexiglas cylinder $(10 \mathrm{~cm}$ internal diameter, $50 \mathrm{~cm}$ high) filled with $25-26^{\circ} \mathrm{C}$ water $(10 \mathrm{~cm}$ height $)$. Duration of the experiment was 6 min; the behavior of the animals was evaluated between the first and sixth minute for $5 \mathrm{~min}$. The immobility time was measured by an observer, who was unaware of the genetic background or drug treatment, using a stopwatch. A mouse was judged to be immobile when it remained floating in the water, making only those movements necessary to keep its head above the water (Porsolt et al., 1977a). Groups were compared using one-way ANOVA; the Dunnett's test was used for post hoc comparisons.

Tail-suspension test. Mice were suspended individually by their tail from a metal rod. The rod was fixed $50 \mathrm{~cm}$ above the surface of a table covered with soft cloth in a sound-isolated room. The tip of the tail was fixed using adhesive Scotch tape; the duration of the test was 6 min. The immobility time was determined by an observer, using a stopwatch, who was unaware of the strain (Steru et al., 1985). Mean values and SEs were calculated for each group and compared using the Student's $t$ test.

Bulbectomy-induced hyperactivity. The experiment was performed with slight modifications as described previously (Otmakhova et al., 1992). Mice were anesthetized with Avertine $(2.5 \%, 20 \mathrm{ml} / \mathrm{kg})$. An incision was made in the skin overlying the skull, and a $2 \mathrm{~mm}$ hole was drilled in the skull through the frontal suture. Olfactory bulbs were removed by gentle aspiration. The same procedure was performed on sham-operated animals, except that the olfactory bulbs were not removed. Each animal was housed singly after surgery. Locomotor activity of animals was studied $14 \mathrm{~d}$ after the operation in a dimly lit, sound-attenuated room. The animals were placed in an open-field arena $(45 \times 45 \times 22 \mathrm{~cm})$. The distance traveled and the number of rearings were recorded for $4 \mathrm{~min}$ (Actimeter, TSE). After completion of the behavioral experiments, mice were decapitated, brains were removed, and the success of the bulbectomy was evaluated. Groups were compared using two-way ANOVA (surgery $\times$ genotype) followed by Student's-Newman-Keuls (SNK) test.

Open-field test. Mice were placed in the center of a brightly lit (650-700 lux) or dimly lit (20-30 lux) chamber of the open-field apparatus $(44 \times$ $44 \times 30 \mathrm{~cm}$ ). Movements of the animals were tracked by an automatic monitoring system (MED Associates) for $20 \mathrm{~min}$. Horizontal motor (distance traveled) and central activity (distance traveled in central area/total distance traveled) were evaluated. Mean value and SE was calculated in each group, which contained 10 animals. Groups were compared using two-way ANOVA (genotype $\times$ illumination) followed by SNK test.

Elevated zero-maze. Mice were kept for at least $1 \mathrm{hr}$ in the normally illuminated room where the treatment and experiment were performed. Animals were treated with saline $\left(\mathrm{Tacl}^{-1-}\right.$ mice and the control $\mathrm{Tac1} \mathrm{I}^{+/+}$ mice) or reference compound (buspirone $1 \mathrm{mg} / \mathrm{kg}$, diazepam $1 \mathrm{mg} / \mathrm{kg}$, or ethanol $2 \mathrm{gm} / \mathrm{kg}$ ) intraperitoneally in a volume of $10 \mathrm{ml} / \mathrm{kg}$; $9-10$ animals were tested in each group. Thirty minutes later their activity on the zero-maze was measured for $5 \mathrm{~min}$. The maze consisted of an annular white platform (inner diameter $46 \mathrm{~cm}, 5.6 \mathrm{~cm}$ width) elevated $40 \mathrm{~cm}$ above ground level and divided equally into four quadrants. The two opposite quadrants were enclosed by white walls $(24 \mathrm{~cm}$ high) on both edges of the platform. The behavior of mice was videotaped using a camera fixed above the maze and analyzed with a video-tracking system (Videomot; TSE GMbH). The number of stretching postures was determined by an experienced observer who was unaware of strain or treatment. Time spent in the open area, distance traveled in the open and closed parts, and number of stretching postures were evaluated (Shepherd et al., 1994; Konig et al., 1996). Mean value and SE were calculated in each group, and groups were compared using one-way ANOVA followed by Dunnett's test.

Thatcher-Britton paradigm. Ten wild-type and $10 \mathrm{knock}-$ out mice were food deprived for $24 \mathrm{hr}$ before testing. During testing, animals were placed individually along one wall of the open-field apparatus lit by normal house lighting (light intensity 300-400 lux in the center of the box). Six pellets (2.8-3.3 gm) of standard mouse chow were placed in the center of the open field. The latency to eat (not sniffing or manipulating the pellets) was recorded by an observer who was unaware of the genotype (Rochford et al., 1997). One week later the experiment was repeated, but in this session the food pellet was presented in the home cage. Mean value and SE were calculated in each group, and groups were compared using Student's $t$ test.

Social interaction test. Social activity of male mice that were naive to each other was tested in a brightly lit, unfamiliar environment. The animals were placed in the opposite areas of a transparent box $(44 \times$ $44 \times 30 \mathrm{~cm}$ ) and separated by a removable wall. After $5 \mathrm{~min}$ of habituation, the wall was removed, and the activity of the animals was recorded on videotapes for $10 \mathrm{~min}$. Time spent with social interactions was registered and evaluated by an observer who was unaware of the genotype (de Angelis and File, 1979). Mean values and SEs were calculated and compared using Student's $t$ test.

Smelling test. Male wild-type and knock-out animals were placed individually into an open field with one female urine-stained and one water-stained filter paper $(3 \times 3 \mathrm{~cm}$ each $)$ in opposite corners. The number of contacts with each paper was evaluated for $5 \mathrm{~min}$. The data were analyzed by two-way ANOVA (genotype $\times$ odorant).

\section{RESULTS}

In the first set of experiments, we tested the behavior of knockout and wild-type mice in animal models commonly used in depression research. We first used the forced-swimming test (Porsolt, 1997; Persolt et al., 1977b) and the tail-suspension test (Steru et al., 1985). Both models are based on the observation that rodents, when forced to an aversive situation from which they cannot escape, will rapidly cease attempts to escape and become immobile. Many antidepressants reduce the immobility time in these tests (Steru et al., 1987; Porsolt, 2000).

In the forced-swimming test, active escape periods alternated with periods in which the animals were completely inactive or made only the movements necessary to keep their head above water. As shown in Figure $1 A, \mathrm{Tacl}^{-1-}$ mice spend less time immobile in this test than $\operatorname{Tacl}^{+/+}$animals. Treatment of wildtype animals with antidepressant drugs, including the tricyclic uptake inhibitors imipramine and amitryptiline, as well as the selective serotonin reuptake inhibitor fluoxetine, significantly reduced immobility time $\left(F_{(4,45)}=6.99 ; p<0.001\right.$; one-way ANOVA) (Fig. $1 A$ ). There was no difference in immobility time between $\mathrm{Tacl}^{-/-}$mice and $\mathrm{Tacl}^{+/+}$animals treated with anti- 

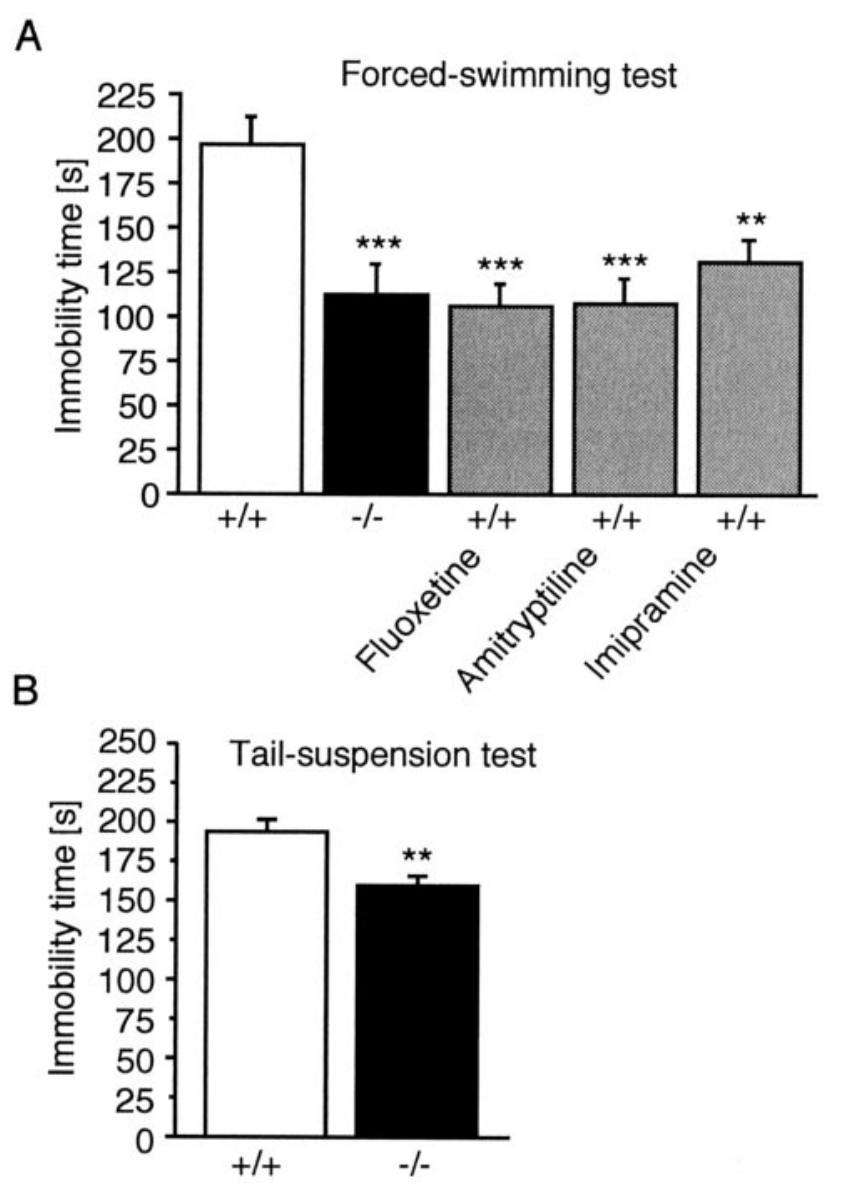

Figure 1. Behavior of $\mathrm{Tacl}^{+/+}$and $\mathrm{Tacl}^{-1-}$ male mice in behavioral despair models of depression. $A$, Forced-swimming test. ${ }^{* *} p<0.01$; *** $p<0.001$ (one-way ANOVA followed by Dunnett's test). B, Tailsuspension test. ${ }^{* *} p<0.01$ (Student's unpaired $t$ test). Each error bar represents the mean time spent in immobility $( \pm$ SEM) of 10 animals.

depressants. In the tail-suspension test, the immobility time in $\mathrm{TaC1}^{-/-}$mice was also reduced significantly $\left(-18.2 \% ; t_{(1,18)}=\right.$ 3.737; $p<0.01$; Student's $t$ test) (Fig. 1B).

We further investigated $T a c 1^{-1-}$ mice in another animal model related to depression that is fundamentally different from the behavioral despair models. For this purpose, we chose the bulbectomy test (Leonard and Tuite, 1981; Otmakhova et al., 1992). Bulbectomy induces behavioral and neuroendocrinal changes, similar to those observed in depressive patients, that can be reversed with antidepressant treatment (Jesberger and Richardson, 1988). There was a significant interaction between strain and surgery in horizontal motor activity $\left(F_{(1,38)}=4.246 ; p<0.05\right.$; ANOVA) and in vertical activity $\left(F_{(1,38)}=5.929 ; p<0.05\right.$; ANOVA) (Fig. 2. Post hoc analysis revealed that horizontal and vertical activity were significantly increased after bulbectomy in Tac1 $^{+/+}$animals (horizontal activity: $+53.8 \%, p<0.001$; vertical activity: $+130.3 \%, p<0.05$; SNK test). In contrast, neither horizontal nor vertical movements were significantly increased in bulbectomized versus sham-operated $\mathrm{Tac1}^{-/-}$animals. Because differences in the ability to smell might affect the animals' behavior in this and other tests, we analyzed the responses of $\mathrm{Tacl}^{-1-}$ mice to olfactory cues. When male $\mathrm{Tacl}^{-/-}$and $\mathrm{Tacl}^{+/+}$mice were presented with a (female) urine-stained or a water-stained filter paper in an open field, both genotypes investigated the urine-stained paper more frequently $\left(F_{(1,17)}=21.6 ; p<0.001\right)$.
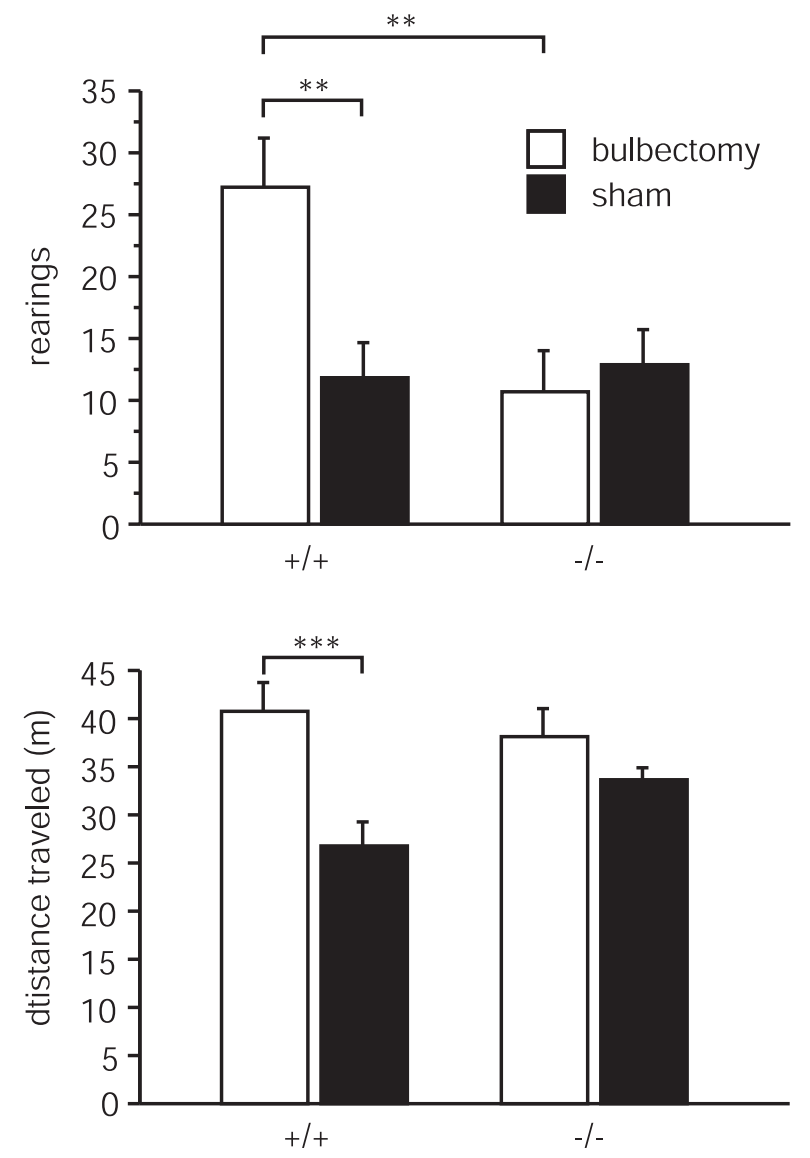

Figure 2. Horizontal (distance traveled) and vertical (number of rearings) motor activity of sham-operated and bulbectomized $\mathrm{Tacl}^{+/+}$and Tac1 $1^{-1-}$ mice in the open-field apparatus. Each value represents the distance traveled or number of rearings (mean \pm SEM; $n=10-11$ ). $* * p<0.01 ; * * * p<0.001$ according to two-way ANOVA (surgery $\times$ genotype) followed by SNK test.

There was no difference between the two genotypes $\left(F_{(1,17)}=\right.$ $1.37 ; p=0.25)$, and also no interaction was detected $\left(F_{(1,17)}=\right.$ $0.85 ; p=0.36)$, indicating that ability to smell was not impaired in $\mathrm{Tacl}^{-1-}$ mice.

We next studied the behaviors of $\mathrm{TaCl}^{-1-}$ and $\mathrm{Tacl}^{+/+}$mice in the open field under aversive (450 lux, white light) and less aversive (2 lux, red light) conditions (Fig. 3). Analysis of the total horizontal activity showed that $\mathrm{TaCl}^{-1-}$ mice were slightly (15.6\%) but significantly less active than $\mathrm{Tacl}^{+/+}$animals (genotype effect: $\left.F_{(1,36)}=6,687 ; p<0.05\right)$. However, there was no significant effect of the lighting condition $\left(F_{(1,36)}=2.479 ; p=\right.$ $0.124)$ and no significant interaction with the genotype effect $\left.\left(F_{(1,36)}=1.121 ; p=0.297\right)\right)$.

It is thought that the activity of mice in the central area of an open field is inversely correlated to their level of anxiety. We therefore analyzed the activity of our animals in the central field. We found a significant interaction between genotype and illumination $\left(F_{(1,36)}=5.077 ; p<0.05\right)$. Post hoc analysis revealed that the activity of $\mathrm{Tac1}^{-1-}$ mice was higher in the central area under high-light conditions $(p<0.0001)$, despite the fact that their overall activity was lower. Under low-light conditions, there was no difference between the two genotypes, because $\mathrm{Tac1}^{-1-}$ mice were not affected by the lightning conditions $(p=0.97)$, whereas the activity of wild-type mice was increased $(p<0.05)$.

Because the results of the open-field experiment suggested that 

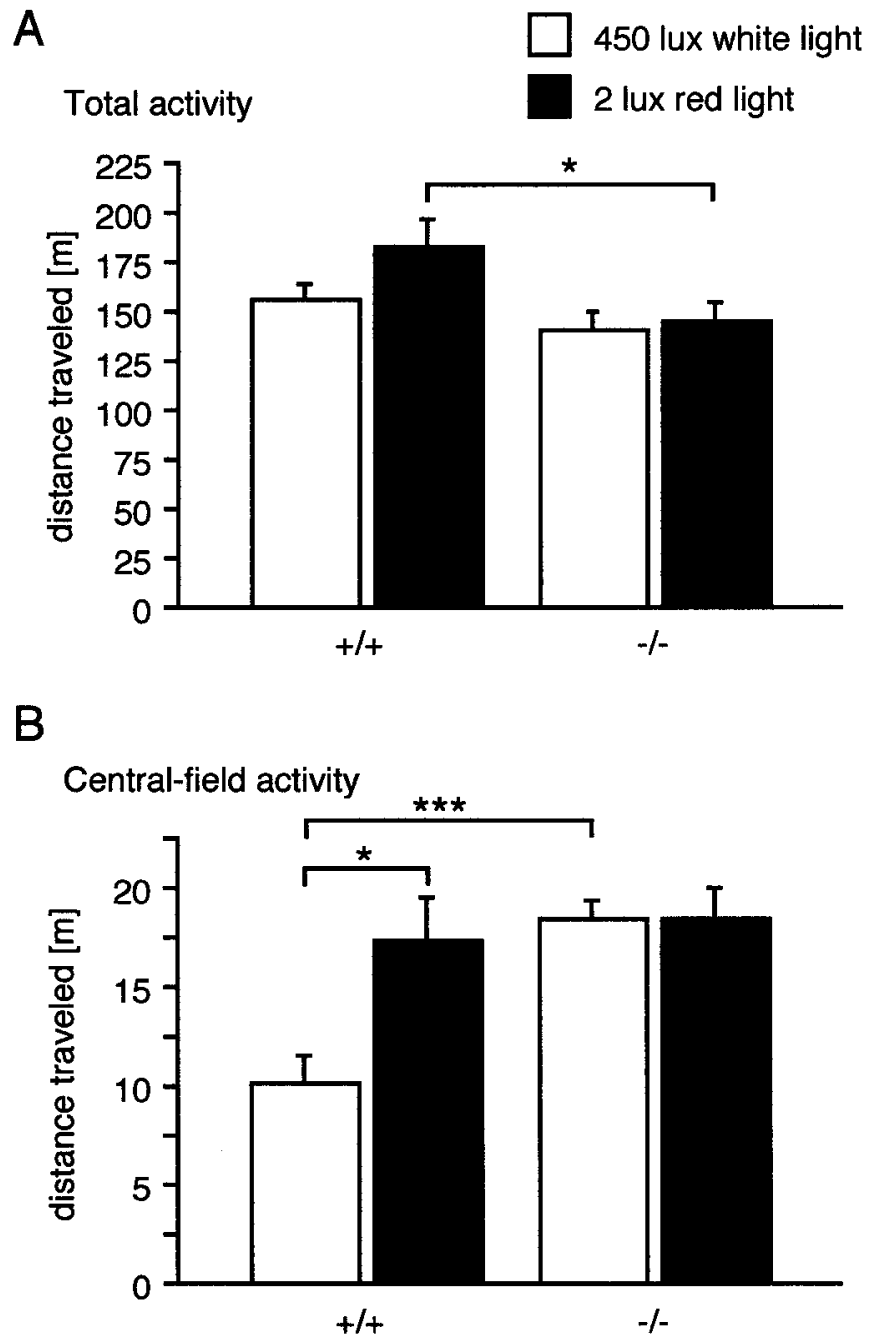

Figure 3. Locomotor activity of $\mathrm{TaCl}^{+/+}$and $\mathrm{Tacl}^{-1-}$ mice in the open-field apparatus. $A$, Total horizontal activity. $B$, Activity in the central part. Each value represents the mean distance traveled ( \pm SEM) of 10 animals. ${ }^{*} p<0.01 ; * * * p<0.001$ according to two-way ANOVA (genotype $\times$ illumination) followed by SNK test.

anxiety-related behaviors may be affected by the Tac1 mutations, we tested $\mathrm{TaCl}^{-/-}$and $\mathrm{Tacl}^{+/+}$mice in additional animal models of anxiety.

We first used the zero-maze, which consists of an elevated annular platform divided into two open and two enclosed compartments. High levels of anxiety are thought to be associated with a reduced activity of mice in the open compartments and an increased number of stretch-attend postures (Shepherd et al., 1994). Indeed, one-way ANOVA showed a significant difference between groups in the number of stretching postures $\left(F_{(4,44)}=\right.$ 9.46; $p<0.001)$ and in the open-part activity $\left(F_{(4,44)}=18.99 ; p<\right.$ $0.001)$. Treatment of wild-type animals with the anxiolytic agents ethanol, buspirone, and diazepam significantly reduced the number of stretch-attend postures (all drugs) and increased the activity in the open areas (ethanol and diazepam only) (Fig. 4). Activity in the enclosed compartment did not differ significantly between $\mathrm{Tacl}^{+/+}$and $\mathrm{Tac1}^{-/-}$or drug-treated mice. $\mathrm{Tacl}^{-/}$ mice were also more active in the open areas than $\mathrm{Tacl}^{+/+}$ animals $(p<0.01)$ and also showed fewer stretch-attend postures $(p<0.001)$. Testing of an independent group of animals for time

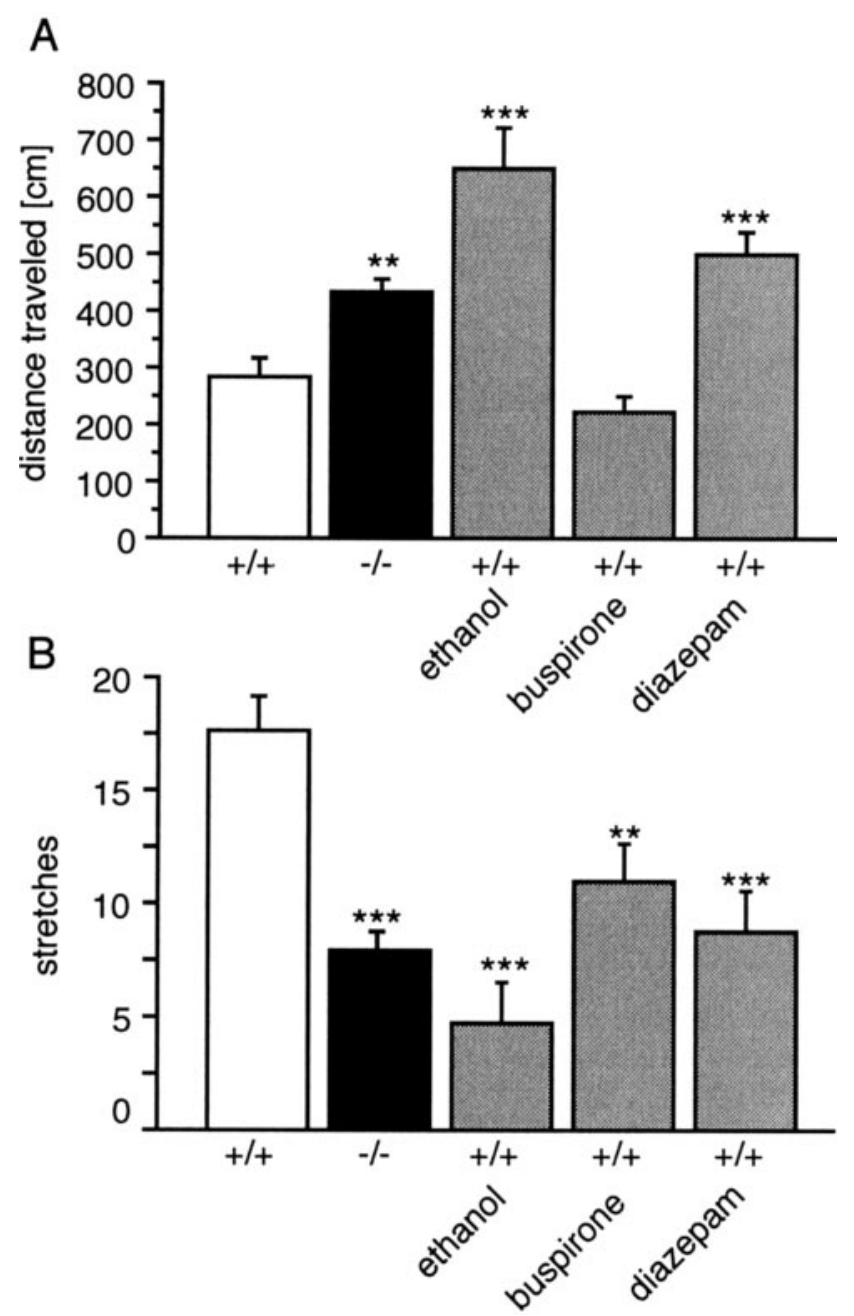

Figure 4. Activity of Tac1 ${ }^{+/+}$control, reference compound-treated, and Tac1 $^{-/-}$knock-out mice in zero-maze test. Error bars represent mean distance traveled in the open part $(A)$ and number of stretching postures (B) $\left( \pm\right.$ SEM) of 10 animals. ${ }^{* *} p<0.01 ; * * p<0.001$ (one-way ANOVA followed by Dunnett's test).

spent in the open areas also revealed a significant genotype effect $\left(F_{(1,18)}=13.88 ; p<0.01\right)$ for this parameter.

Next, the Thatcher-Britton novelty conflict paradigm (Rochford et al., 1997) was used to evaluate the effect of an aversive environment on feeding behavior. In this paradigm, fooddeprived mice are placed at the periphery of a well lit and unfamiliar open-field apparatus in contact with the enclosing walls, with food pellets in the center. The latency until the animals begin to eat is thought to be an indicator of anxiety. It was significantly lower $\left(-33.1 \% ; t_{(1,18)}=3.31 ; p<0.01\right.$; Student's $t$ test) in $\mathrm{Tacl}^{-1-}$ mice (Fig. $5 A$ ). In contrast, when the same animals were tested after $24 \mathrm{hr}$ of starvation in their home cage, there was no difference between the two genotypes $\left(t_{(1,18)}=\right.$ $0.895 ; p=0.38$; data not shown). Thus, the decreased latency in the first experiment is also likely to reflect a reduced state of anxiety in $\mathrm{TaCl}^{-1-}$ mice and not an increased drive to eat.

Finally, a social activity paradigm (File, 1985) was used to study the interactions of male mice that were naive to each other in an aversive environment. Time spent with social interactions was significantly higher $\left(+81 \% ; t_{(1,18)}=2.802 ; p<0.05\right.$; Student's $t$ test) in $\mathrm{Tacl}^{-1-}$ mice (Fig. $5 B$ ), again indicating reduced levels 
A

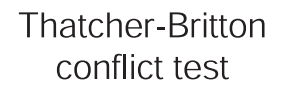

Thatcher-Britton conflict test

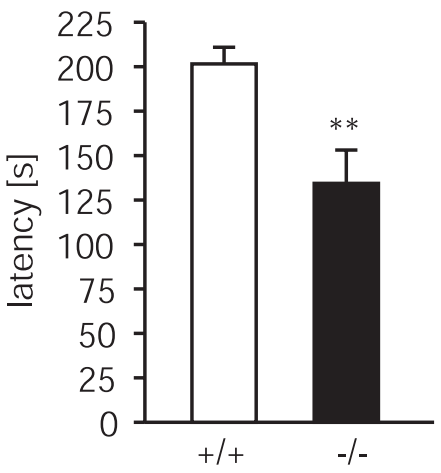

\section{B Social interaction test}

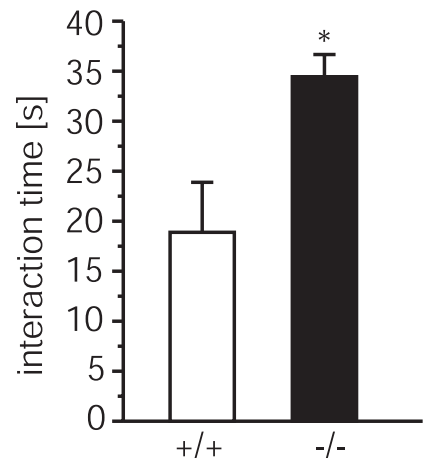

Figure 5. A, Thatcher-Britton novelty conflict paradigm. Error bars represent mean latency time until eating in the center of the lit open arena $( \pm \mathrm{SEM})$ of 10 animals. $B$, Social interaction test. Each column represents time spent with social activity in unfamiliar and aversive (high light) environment $( \pm \mathrm{SEM})$ of 10 animals. ${ }^{*} p \leq 0.05$; ${ }^{*} p \leq 0.01$ (Student's unpaired $t$ test).

of anxiety in these animals. The social behavior of the animals was friendly and exploratory; antagonistic behaviors were not observed. Altogether these results strongly suggest that $\mathrm{Tac1}^{-1-}$ mice were less anxious in these animal models than $\mathrm{Tacl}^{+/+}$ animals.

\section{DISCUSSION}

The murine Tacl gene encodes the tachykinin peptides SP, NKA, neuropeptide K, and neuropeptide $\gamma$. SP binds preferentially to the NK1R, which is abundantly expressed in many regions of the CNS. The primary target of the other Tac1-derived peptides is the NK2 receptor, which can only be found at low levels in some restricted brain areas (Saffroy et al., 2001).

In this article, we have analyzed $\mathrm{Tacl}^{-1-}$ mice in animal models related to anxiety and depression. On the basis of the clinical association of depressive episodes and stressful life events, many of the animal models for the evaluation of antidepressant drug activity assess stress-precipitated behaviors. The two most widely used animal models for antidepressant drug screening are the forced-swimming and tail-suspension tests. Although the relationship between immobility, a posture thought to reflect a state of "behavioral despair" in which animals have given up the hope of escape, and depression remains controversial (Gardier and Bourin, 2001), drugs with antidepressant activity reduce the time during which the animals remain immobile (Porsolt et al., 1977a; Borsini and Meli, 1988). A significantly decreased immobility time in the forced-swimming test was also observed in genetically modified mouse strains, for example with a deletion of monoamine oxidase (MAO) A (Cases et al., 1995), MAO B (Grimsby et al., 1997), or the NK1 receptor gene (Rupniak et al., 2001). Several studies using inbred mouse strains have also shown that genetic factors contribute to the behavior of rodents in these tests (Lucki et al., 2001; Cryan et al., 2002) and to the efficacy of antidepressant drug treatment (Vaugeois et al., 1997; Liu and Gershenfeld, 2001).

In our present study we found a significantly reduced immobility time for $\mathrm{Tacl}^{-1-}$ mice in both tests. These behavioral effects of the $\mathrm{TaCl}^{-1-}$ mutation are similar to those that we and other investigators have observed after treatment with antidepressant drugs, including MAO inhibitors, tricyclic antidepressants such as

imipramine and amitryptiline, or selective serotonin reuptake inhibitors like fluoxetine (Porsolt et al., 1977a; Borsini and Meli, 1988). $\mathrm{Tacl}^{-/-}$and $\mathrm{Tacl}^{+/+}$mice showed characteristically uniform responses with only a small overlap between the two genotypes. Thus, the Tac1 gene is an important determining factor in these behavioral despair models. A recent quantitative trait loci (QTL) study has identified several genetic links to the propensity of behavioral despair using the same assays (Yoshikawa et al., 2002). Unexpectedly, only a small number of QTLs were shared, and one common QTL on chromosome 8 displayed opposite effects in the two tests. Thus, although the test paradigms appear to be similar, distinct genetic pathways may underlie the despairlike behaviors in these tests. This idea is supported by the common observation that most antidepressant drugs have different pharmacological profiles in the forced-swimming and tailsuspension tests. Nevertheless, the Tac1 mutation significantly reduced the immobility time in both tests, although to a smaller extend in the tail-suspension test $(-42.29$ vs $-18.2 \%)$.

Further evidence for a role of the Tac1 gene in depressionrelated behaviors comes from the lack of bulbectomy-induced hyperactivity in $\mathrm{Tacl}^{-1-}$ mice. The bulbectomy test is fundamentally different from the forced-swimming or tail-suspension tests. It does not involve the concept of behavioral despair, but rather relies on the observation that bulbectomy will induce behavioral changes in rodents that can be reversed by chronic antidepressant treatment (Otmakhova et al., 1992).

Our results strongly support the idea that the tachykinin system is involved in the pathophysiology of depression. Such a role was suggested by a clinical study that demonstrated the efficacy of the NK1 receptor antagonist MK869 in patients with a major depressive disorder (Kramer et al., 1998). In this clinical study, MK869 showed an efficacy similar to that of paroxetine.

There is evidence to suggest that some antidepressant drugs lead to a downregulation of SP biosynthesis (Shirayama et al., 1996), although it has been difficult to establish a direct relationship between the level of SP expression and depression. In Flinders Sensitive Line rats, an animal model of depression, Husum and coworkers (2001) found that brain levels of SP were reduced in the striatum and elevated in the frontal cortex. These levels were normalized after treatment with lithium (Husum et al., 2001). In humans, one study indicated that SP levels are elevated in the CSF of depressed patients (Rimon et al., 1984).

The behavior of $\mathrm{TaCl}^{-1-}$ mice was also analyzed in several animal models of anxiety. In the open-field test (lit environment), $\mathrm{TaCl}^{+/+}$mice spent only $6.5 \%$ of their total activity in the central part, which represents $11 \%$ of the total area. In contrast, Tac1 ${ }_{-1-}$ mice spent $13.6 \%$ of their activity in the central area. These results indicate that the testing conditions were anxiogenic for $\mathrm{Tacl}^{+/+}$animals but not for $\mathrm{Tacl}^{-/-}$mice. $\mathrm{Tacl}^{-/-}$mice were more active in the open part of the zero-maze and showed fewer stretching postures. Knock-out mice spent more time with social interactions in an aversive environment, and the latency time until eating was reduced in the Thatcher-Britton paradigm. In summary, all of our results from the four different animal models indicate that Tacl-deficient mice were generally less emotional than control animals.

These findings are in general agreement with the recent demonstration that pharmacological blockade of the SP receptor NK1 influenced emotional responses in animals (File, 1997, 2000; Cheeta et al., 2001; Rupniak et al., 2001). However, the pharmacological analysis of NK1 receptor functions has been complicated by the fact that small differences in the amino acid sequence 
between human and mouse or rat receptors dramatically alter antagonist binding affinity (Fong et al., 1992). Thus, antagonists with a high affinity for human receptor cannot be evaluated in rats or mice. Although a few antagonists with nanomolar affinities for the rat and mouse receptor, such as RP67580, GR205171, and SR140333, have been developed (Fong et al., 1992; Emonds-Alt et al., 1993; Gardner et al., 1996), the usefulness of these compounds in vivo suffers from their short half-life and poor brain penetration. At bioactive doses these compounds can exhibit unspecific pharmacological effects, including the blockade of ion channels. Therefore it was often difficult to ascertain whether behavioral effects of these drugs were caused by NK1 receptor blockade or some unspecific effect. For example, high doses of GR205171 (30 mg/kg), which is probably the best available antagonist for the murine NK1 receptor (Bergstrom et al., 2000), increased the attack latency in the resident-intruder test, reduced stress-induced neonatal vocalization, and increased the duration of struggle in the forced-swimming test (Rupniak et al., 2000, 2001). These effects were similar to those observed after treatment with antidepressant drugs such as fluoxetine or desipramine (Lucki et al., 2001; Rupniak et al., 2001; Schramm et al., 2001). However, it is not clear whether these behavioral effects of GR205171 were mediated by the NK1 receptor, because animals responded similarly after treatment with the low-affinity enantiomer GR22620600 (Rupniak et al., 2000). Also, in the rat forcedswimming test, GR205171 (40 $\mathrm{mg} / \mathrm{kg})$ remained ineffective (Rupniak et al., 2001).

Separate laboratories produced mice with targeted NK1 receptor gene deletions with different genetic background (De Felipe et al., 1998; Santarelli et al., 2001). A role for the NK1 receptor in the modulation of emotional states was also suggested by the analysis of these knock-out animals. $\mathrm{NK} 1^{-/-}$animals from both strains emitted fewer ultrasonic calls after maternal separation (Rupniak et al., 2000; Santarelli et al., 2001), and they were more active in the forced-swimming test (Rupniak et al., 2001). De Felipe et al. (1998) also found that $\mathrm{NK} 1^{-/-}$animals were less aggressive than wild-type littermates. In the elevated plus maze, however, the results were contradictory. Murtra et al. (2000) and Rupniak et al. (2001) saw no difference between $\mathrm{NK} 1^{-/-}$and $\mathrm{NK} 1^{+/+}$animals, whereas Santarelli et al. (2001) found that $\mathrm{NK} 1^{-/-}$mice have a decreased level of anxiety according to this model. The reason for this discrepancy can be that the genetic background of the knock-out mice was different in these studies [pure 129/sv in the studies of Santarelli et al. (2001), whereas $129 / \mathrm{sv}$ and C57BL/6J were used in the studies of Murtra et al. (2000) and Rupniak et al. (2001)]. Pharmacological studies also produced conflicting results with this test, with RP67580 being effective but not GR205171. Although it is unclear whether these differences are attributable to different experimental procedures or strain background, we show here that the Tac1 gene deletion had a clear behavioral effect in a similar animal model of anxiety, the zero-maze.

Considering (1) the similarity of the Tac1 mutant phenotype with the behavioral effects of the genetic deletion or pharmacological blockade of the NK1R and (2) the fact that NK1R is widely expressed in the CNS whereas NK2R expression is weak and restricted, many of the functions of Tac1-derived neuropeptides on the brain may be mediated by NK1R. However, SR48968, a selective antagonist of NK2 receptor, had an enantioselective effect in specific models related to anxiety (Griebel et al., 2001) or depression (Steinberg et al., 2001). Thus, both receptors may serve as targets for Tac1-derived neuropeptides in the brain.
The serotonergic system has been suggested as a potential target for effects of tachykinins on depression-related behaviors. Indeed, NK1R antagonism resulted in an increased firing of serotonergic neurons and attenuated presynaptic 5-HT1A receptors, similar to what has been observed after long-term antidepressant treatment (De Felipe et al., 1998; Santarelli et al., 2001). A recent analysis of inducible 5-HT1A receptor knock-out mice demonstrated that the absence of this receptor during early postnatal development had similar effects on anxiety-related behaviors as the unconditional mutation (Gross et al., 2002). This result suggests a critical developmental period in the manifestation of anxiety-related phenotypes. Further studies are necessary to determine whether developmental or compensatory mechanisms also contribute to the phenotypic changes observed in Tac1 mutant animals.

Together these experiments support the idea that SP and other Tac1-derived neuropeptides play a major role in anxiety and depression. Therefore, modulation of the SP-NK1 system may have therapeutic value in the treatment of stress-related neuropsychiatric disorders.

\section{REFERENCES}

Bergstrom M, Fasth KJ, Kilpatrick G, Ward P, Cable KM, Wipperman MD, Sutherland DR, Langstrom B (2000) Brain uptake and receptor binding of two $\left[{ }^{11} \mathrm{C}\right]$ labeled selective high affinity NK1-antagonists, GR203040 and GR205171-PET studies in rhesus monkey. Neuropharmacology 39:664-670.

Borsini F, Meli A (1988) Is the forced swimming test a suitable model for revealing antidepressant activity? Psychopharmacology (Berl) 94:147-160.

Cao YQ, Mantyh PW, Carlson EJ, Gillespie AM, Epstein CJ, Basbaum AI (1998) Primary afferent tachykinins are required to experience moderate to intense pain. Nature 392:390-394.

Cases O, Seif I, Grimsby J, Gaspar P, Chen K, Pournin S, Muller U, Aguet M, Babinet C, Shih JC (1995) Aggressive behavior and altered amounts of brain serotonin and norepinephrine in mice lacking MAOA. Science 268:1763-1766.

Cheeta S, Tucci S, Sandhu J, Williams AR, Rupniak NM, File SE (2001) Anxiolytic actions of the substance $\mathrm{P}$ (NK1) receptor antagonist L-760735 and the 5-HT1A agonist 8-OH-DPAT in the social interaction test in gerbils. Brain Res 915:170-175.

Cryan JF, Markou A, Lucki I (2002) Assessing antidepressant activity in rodents: recent developments and future needs. Trends Pharmacol Sci 23:238-245.

de Angelis L, File SE (1979) Acute and chronic effects of three benzodiazepines in the social interaction anxiety test in mice. Psychopharmacology 64:127-129.

De Felipe C, Herrero JF, O'Brien JA, Palmer JA, Doyle CA, Smith AJ, Laird JM, Belmonte C, Cervero F, Hunt SP (1998) Altered nociception, analgesia and aggression in mice lacking the receptor for substance P. Nature 392:394-397.

Emonds-Alt X, Doutremepuich JD, Heaulme M, Neliat G, Santucci V, Steinberg R, Vilain P, Bichon D, Ducoux JP, Proietto V (1993) In vitro and in vivo biological activities of SR140333, a novel potent non-peptide tachykinin NK1 receptor antagonist. Eur J Pharmacol 250:403-413.

File SE (1985) Animal models for predicting clinical efficacy of anxiolytic drugs: social behaviour. Neuropsychobiology 13:55-62.

File SE (1997) Anxiolytic action of a neurokinin1 receptor antagonist in the social interaction test. Pharmacol Biochem Behav 58:747-752.

File SE (2000) NKP608, an NK1 receptor antagonist, has an anxiolytic action in the social interaction test in rats. Psychopharmacology (Berl) 152:105-109.

Fong TM, Yu H, Strader CD (1992) Molecular basis for the species selectivity of the neurokinin-1 receptor antagonists CP-96, 345 and RP67580. J Biol Chem 267:25668-25671.

Gardier AM, Bourin M (2001) Appropriate use of "knockout" mice as models of depression or models of testing the efficacy of antidepressants. Psychopharmacology (Berl) 153:393-394.

Gardner CJ, Armour DR, Beattie DT, Gale JD, Hawcock AB, Kilpatrick GJ, Twissell DJ, Ward P (1996) GR205171: a novel antagonist with high affinity for the tachykinin NK1 receptor, and potent broadspectrum anti-emetic activity. Regul Pept 65:45-53.

Griebel G, Perrault G, Soubrie P (2001) Effects of SR48968, a selective non-peptide $\mathrm{NK} 2$ receptor antagonist on emotional processes in rodents. Psychopharmacology (Berl) 158:241-251.

Grimsby J, Toth M, Chen K, Kumazawa T, Klaidman L, Adams JD, 
Karoum F, Gal J, Shih JC (1997) Increased stress response and betaphenylethylamine in MAOB-deficient mice. Nat Genet 17:206-210.

Gross C, Zhuang X, Stark K, Ramboz S, Oosting R, Kirby L, Santarelli L, Beck S, Hen R (2002) Serotonin1A receptor acts during development to establish normal anxiety-like behaviour in the adult. Nature 416:396-400.

Honkaniemi J, Pelto-Huikko M, Rechardt L, Isola J, Lammi A, Fuxe K, Gustafsson JA, Wikstrom AC, Hokfelt T (1992) Colocalization of peptide and glucocorticoid receptor immunoreactivities in rat central amygdaloid nucleus. Neuroendocrinology 55:451-459.

Hurd YL, Keller E, Sotonyi P, Sedvall G (1999) Preprotachykinin-A mRNA expression in the human and monkey brain: an in situ hybridization study. J Comp Neurol 411:56-72.

Husum H, Vasquez PA, Mathe AA (2001) Changed concentrations of tachykinins and neuropeptide $\mathrm{Y}$ in brain of a rat model of depression: lithium treatment normalizes tachykinins. Neuropsychopharmacology 24:183-191.

Jesberger JA, Richardson JS (1988) Brain output dysregulation induced by olfactory bulbectomy: an approximation in the rat of major depressive disorder in humans? Int J Neurosci 38:241-265.

Konig M, Zimmer AM, Steiner H, Holmes PV, Crawley JN, Brownstein MJ, Zimmer A (1996) Pain responses, anxiety and aggression in mice deficient in pre-proenkephalin. Nature 383:535-538.

Kramer MS, Cutler N, Feighner J, Shrivastava R, Carman J, Sramek JJ, Reines SA, Liu G, Snavely D, Wyatt-Knowles E, Hale JJ, Mills SG, MacCoss M, Swain CJ, Harrison T, Hill RG, Hefti F, Scolnick EM, Cascieri MA, Chicchi GG, et al. (1998) Distinct mechanism for antidepressant activity by blockade of central substance P receptors. Science 281:1640-1645.

Leonard BE, Tuite M (1981) Anatomical, physiological, and behavioral aspects of olfactory bulbectomy in the rat. Int Rev Neurobiol 22:251-286.

Liu X, Gershenfeld HK (2001) Genetic differences in the tail-suspension test and its relationship to imipramine response among 11 inbred strains of mice. Biol Psychiatry 49:575-581.

Lucki I, Dalvi A, Mayorga AJ (2001) Sensitivity to the effects of pharmacologically selective antidepressants in different strains of mice. Psychopharmacology (Berl) 155:315-322.

Murtra P, Sheasby AM, Hunt SP, De Felipe C (2000) Rewarding effects of opiates are absent in mice lacking the receptor for substance P. Nature 405:180-183.

Otmakhova NA, Gurevich EV, Katkov YA, Nesterova IV, Bobkova NV (1992) Dissociation of multiple behavioral effects between olfactory bulbectomized C57BL/6J and DBA/2J mice. Physiol Behav 52:441-448.

Porsolt RD (1997) Historical perspective on CMS model. Psychopharmacology (Berl) 134:363-364, 371-367.

Porsolt RD (2000) Animal models of depression: utility for transgenic research. Rev Neurosci 11:53-58.

Porsolt RD, Bertin A, Jalfre M (1977a) Behavioral despair in mice: a primary screening test for antidepressants. Arch Int Pharmacodyn Ther 229:327-336

Porsolt RD, Le Pichon M, Jalfre M (1977b) Depression: a new animal model sensitive to antidepressant treatments. Nature 266:730-732.

Ribeiro-da-Silva A, Hokfelt T (2000) Neuroanatomical localisation of substance $\mathrm{P}$ in the CNS and sensory neurons. Neuropeptides $34: 256-271$.

Rimon R, Le Greves P, Nyberg F, Heikkila L, Salmela L, Terenius L (1984) Elevation of substance P-like peptides in the CSF of psychiatric patients. Biol Psychiatry 19:509-516.

Rochford J, Beaulieu S, Rousse I, Glowa JR, Barden N (1997) Behav- ioral reactivity to aversive stimuli in a transgenic mouse model of impaired glucocorticoid (type II) receptor function: effects of diazepam and FG-7142. Psychopharmacology (Berl) 132:145-152.

Rupniak NM, Carlson EC, Harrison T, Oates B, Seward E, Owen S, de Felipe C, Hunt S, Wheeldon A (2000) Pharmacological blockade or genetic deletion of substance $\mathrm{P}(\mathrm{NK}(1))$ receptors attenuates neonatal vocalisation in guinea-pigs and mice. Neuropharmacology 39:1413-1421.

Rupniak NM, Carlson EJ, Webb JK, Harrison T, Porsolt RD, Roux S, de Felipe C, Hunt SP, Oates B, Wheeldon A (2001) Comparison of the phenotype of NK1R-/- mice with pharmacological blockade of the substance P (NK1) receptor in assays for antidepressant and anxiolytic drugs. Behav Pharmacol 12:497-508.

Saffroy M, Torrens Y, Glowinski J, Beaujouan JC (2001) Presence of NK2 binding sites in the rat brain. J Neurochem 79:985-996.

Santarelli L, Gobbi G, Debs PC, Sibille ET, Blier P, Hen R, Heath MJ (2001) Genetic and pharmacological disruption of neurokinin 1 receptor function decreases anxiety-related behaviors and increases serotonergic function. Proc Natl Acad Sci USA 98:1912-1917.

Schramm NL, McDonald MP, Limbird LE (2001) The alpha(2a)adrenergic receptor plays a protective role in mouse behavioral models of depression and anxiety. J Neurosci 21:4875-4882.

Shepherd JK, Grewal SS, Fletcher A, Bill DJ, Dourish CT (1994) Behavioural and pharmacological characterisation of the elevated "zeromaze" as an animal model of anxiety. Psychopharmacology (Berl) 116:56-64.

Shirayama Y, Mitsushio H, Takashima M, Ichikawa H, Takahashi K (1996) Reduction of substance P after chronic antidepressants treatment in the striatum, substantia nigra and amygdala of the rat. Brain Res 739:70-78.

Steinberg R, Alonso R, Griebel G, Bert L, Jung M, Oury-Donat F, Poncelet M, Gueudet C, Desvignes C, Le Fur G, Soubrie P (2001) Selective blockade of neurokinin-2 receptors produces antidepressantlike effects associated with reduced corticotropin-releasing factor function. J Pharmacol Exp Ther 299:449-458.

Steru L, Chermat R, Thierry B, Simon P (1985) The tail suspension test: a new method for screening antidepressants in mice. Psychopharmacology 85:367-370.

Steru L, Chermat R, Thierry B, Mico JA, Lenegre A, Steru M, Simon P, Porsolt RD (1987) The automated tail suspension test: a computerized device which differentiates psychotropic drugs. Prog Neuropsychopharmacol Biol Psychiatry 11:659-671.

Teixeira RM, Santos AR, Ribeiro SJ, Calixto JB, Rae GA, De Lima TC (1996) Effects of central administration of tachykinin receptor agonists and antagonists on plus-maze behavior in mice. Eur $\mathbf{J}$ Pharmacol 311:7-14.

Vaugeois JM, Passera G, Zuccaro F, Costentin J (1997) Individual differences in response to imipramine in the mouse tail suspension test. Psychopharmacology (Berl) 134:387-391.

Yoshikawa T, Watanabe A, Ishitsuka Y, Nakaya A, Nakatani N (2002) Identification of multiple genetic loci linked to the propensity for "behavioral despair" in mice. Genome Res 12:357-366.

Zernig G, Troger J, Saria A (1993) Different behavioral profiles of the non-peptide substance P (NK1) antagonists CP-96, 345 and RP 67580 in Swiss albino mice in the black-and-white box. Neurosci Lett 151:64-66.

Zimmer A, Zimmer AM, Baffi J, Usdin T, Reynolds K, Konig M, Palkovits M, Mezey E (1998) Hypoalgesia in mice with a targeted deletion of the tachykinin 1 gene. Proc Natl Acad Sci USA 95:26302635. 